\title{
Resistência da madeira ao cisalhamento paralelo às fibras segundo as normas ABNT NBR 7190:1997 e ISO 13910:2005
}

\author{
Shear strength of wood in direction parallel \\ to the grain according to the standards \\ ABNT NBR 7190:1997 and ISO 13910:2005
}

Gabriela da Silva Matos ${ }^{1}$, Julio Cesar Molina ${ }^{2}$

\footnotetext{
${ }^{1}$ Universidade Paulista “Júlio de Mesquita Filho” - UNESP - Itapeva, SP e-mail: gabriela.matos@grad.itapeva.unesp.br

${ }^{2}$ Universidade Paulista "Júlio de Mesquita Filho" - UNESP - Itapeva, SP e-mail:molina@itapeva.unesp.br
}

\section{RESUMO}

O conhecimento das propriedades físicas e mecânicas da madeira é essencial para o seu correto destino e uso final. Para uso estrutural, as normas técnicas estabelecem metodologias de ensaios para a determinação das propriedades mecânicas. No Brasil a norma para estruturas de madeira [1] atualmente encontra-se em processo de revisão. Uma das propostas da versão de revisão é a alteração de alguns procedimentos de ensaios usados na determinação das propriedades mecânicas da madeira. Tem-se observado que vários modelos de corpos de prova também vêm sendo testados pela comissão de estudos CE - 02:126.10 da Associação Brasileira de Normas Técnicas para determinação de um modelo mais representativo para os ensaios. Dentro deste contexto, o objetivo deste estudo foi analisar a resistência ao cisalhamento através da atual norma brasileira [1] e também a partir da norma europeia [2]. Foram também avaliadas as relações simplificadas entre as resistências ao cisalhamento e à compressão paralela as fibras $\left(\mathrm{f}_{\mathrm{v} 0, \mathrm{k}} / \mathrm{f}_{\mathrm{c} 0, \mathrm{k}}\right)$ propostas pela norma brasileira [1] para coníferas e dicotiledôneas. Foram consideradas neste estudo madeiras de Pinus elliottii e Eucalyptus saligna. Os resultados obtidos mostraram que a norma brasileira apresentou valores maiores para a resistência de cisalhamento com relação à norma europeia. Para as madeiras de eucalipto e pinus estudadas, as diferenças entre as resistências de cisalhamento foram, respectivamente, 35\% e 65\%, neste caso, e a relação simplificada $\left(\mathrm{f}_{\mathrm{v} 0, \mathrm{k}} / \mathrm{f}_{\mathrm{c} 0, \mathrm{k}}\right)$ obtida para o eucalipto foi a que mais se aproximou dos valores normatizados pela norma brasileira [1].

Palavras-chave: cisalhamento, resistência, normatização.

\begin{abstract}
Knowing the physical, and mechanical wood properties is essential for its proper destination and its final use. For the structural use, technical standards establish methodologies tests to determine the mechanical properties. In Brazil, the standard for wooden structures [1] is currently under review. Part of the proposals for the revision version include the review of the mechanical properties tests methods. It has been noted that several specimens for the tests methods has been tested by the commission of CE studies - 02: 126.10 of the Brazilian Technical Standards Association to determine the most representative model for the tests. Within this context, the aim of this study was to analyze the shear strength parallel to the grain using the current version of the Brazilian standard [1] and from the European standard [2]. The simplified relationship between shear strength and compression parallel to the grain $\left(\mathrm{f}_{\mathrm{v} 0, \mathrm{k}} / \mathrm{f}_{\mathrm{c} 0}\right)$ proposed by the Brazilian standard [1] was studied as well. This study considered specimens of Pinus elliottii and Eucalyptus saligna. The results showed that the Brazilian standard had higher values for shear strength than the European standard. The differences in the shear strength parallel to the grain between Eucalyptus saligna and Pinus elliottii considering the two standards were approximately $35 \%$ and $65 \%$, respectively, and the simplified relationship $\left(\mathrm{f}_{\mathrm{v} 0, \mathrm{k}} / \mathrm{f}_{\mathrm{c} 0, \mathrm{k}}\right)$ obtained for the eucalipto was that most agree with the values proposed by the Brazilian standard [1].
\end{abstract}


Keywords: shear, strength, standardization.

\section{INTRODUÇÃO}

O conhecimento das propriedades dos materiais é muito importante para a determinação do seu uso em diversas aplicações. No caso da madeira, em especial, observa-se variações de suas propriedades anatómicas, físicas e mecânicas até mesmo ao longo do comprimento de uma mesma peça. A madeira por ser um material natural apresenta variações de umidade, resistência, elasticidade, entre outras propriedades, que podem ocorrer em função da variação do ângulo das fibras, assim como devido à presença de outros defeitos. A madeira é também conhecida por suas características de ortotropia que diferencia ainda as suas propriedades em três diferentes direções ortogonais, conforme ilustra a Figura 1, o que não ocorre com outros materiais conhecidos utilizados na construção civil como o aço e o concreto. Na maioria das vezes a direção paralela às fibras é tomada como referência para a determinação das propriedades da madeira.

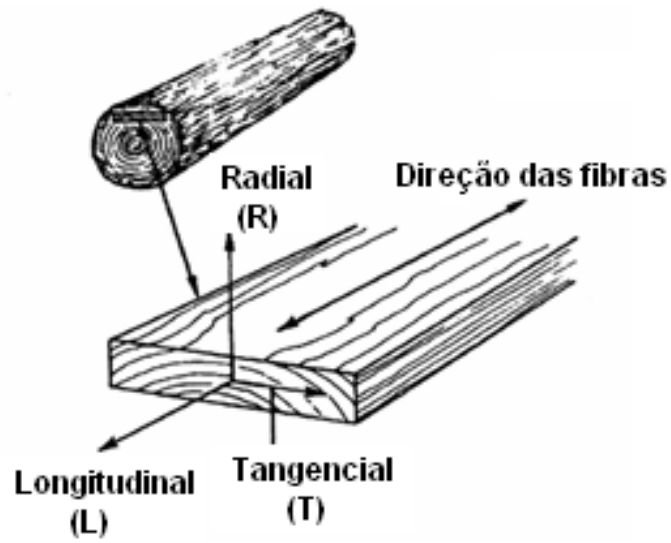

Figura 1: Direções ortogonais da madeira convencional. Fonte: Modificado de RITTER [3].

Para uso em estruturas, se a escolha de uma espécie de madeira não for adequada em função principalmente da sua classe de resistência, a qual pode variar segundo a norma brasileira de madeiras [1] entre 20MPa e 60MPa, poder-se-á observar a ocorrência de danos estruturais, e consequentemente possíveis riscos a vida humana por má utilização do material. Além disso, a proteção química é fundamental para aumentar a longevidade da estrutura de madeira e pode ser feita em autoclave com uma solução de sais de CCA (Cobre, Cromo e Arsênio). As normas técnicas propõem métodos de cálculos e procedimentos de ensaios entre outras especificações visando o melhor aproveitamento do material em questão.

No Brasil a comissão técnica responsável pela proposição e revisão da norma de estruturas de madeira é a CE - 02:126.10 da Associação Brasileira de Normas Técnicas. Atualmente, a norma brasileira de madeiras [1] encontra-se em processo de revisão e, nesse contexto, será proposto um "método de ensaio", pela norma brasileira [1], que substituirá o atual ANEXO B (que contém os principais procedimentos de ensaio para estruturas de madeira) do corpo principal da referida norma. O "método de ensaio" será, portanto, uma norma independente contendo os principais ensaios a serem realizados envolvendo a madeira. Uma das recomendações do "método de ensaio" será o ensaio em corpos de prova isentos de defeitos (o qual já é apresentado na versão de 1997) além de recomendações para ensaios em elementos com dimensões estruturais com dimensões reais. Nesse sentido, vários ensaios têm sido realizados pelos membros da comissão de estudos CE - 02:126.10, considerando diferentes normas internacionais, na intenção de definir métodos de ensaio e modelos de corpos de prova mais representativos para a obtenção das propriedades mecânicas de interesse da madeira.

O modelo de corpo de prova para o ensaio de cisalhamento proposto pela norma brasileira [1], tem sido motivo de discussão principalmente devido a não simetria do mesmo, que pode ocasionar o surgimento de excentricidades durante o ensaio. Também tem se discutido com frequência valor elevado da resistência ao cisalhamento obtido pelo ensaio do corpo de prova proposto pelo anexo B da norma brasileira [1], conforme apresentado na Figura 2, quando o mesmo é comparado com outras normas internacionais, que fornecem valores menores de resistência.

SANTOS NETO [4] realizou um estudo numérico por meio de simulação computacional com base no Método dos Elementos Finitos (MEF) para avaliar as tensões em corpos de prova de cisalhamento propostos pela norma brasileira [1]. O autor considerou elementos sólidos na confecção do modelo numérico e concluiu 
que esse modelo de corpo de prova apresenta excentricidade e isso pode gerar um conjunto de tensões resultante de efeitos de momento fletor e nem sempre de cisalhamento puro como se espera em um ensaio desta natureza. As tensões de cisalhamento puro e àquelas devidas aos efeitos de momento fletor geradas por excentricidade são apresentadas na Figura 2. Outros trabalhos sobre as propriedades de resistência da madeira foram desenvolvidos por SCANAVACA JUNIOR e GARCIA [5], NASCIMENTO et al. [6], RODRIGUES [7], HARA [8], XAVIER [9] e BRAND et al. [10].

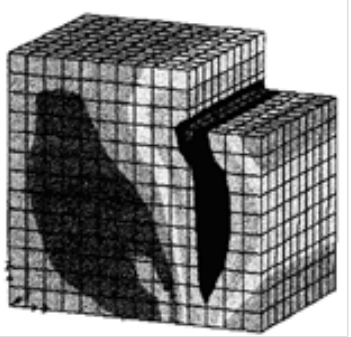

Tensões de cisalhamento no plano de ruptura

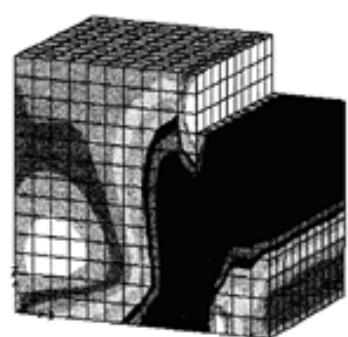

Tensões geradas por excentricidade

Figura 2: Distribuições das tensões em corpos de prova de cisalhamento pelo MEF. Fonte: [4].

Por outro lado, a norma europeia [2] propõe que a determinação da resistência ao cisalhamento da madeira seja obtida a partir de um ensaio de flexão realizado com base em um corpo de prova simétrico, de modo que este trabalhe como uma viga bi-apoiada, com carga concentrada no meio do vão. A relação entre a distância entre apoios (L) e a altura (h) do corpo de prova, neste caso, é admitida como sendo menor que 20. Neste caso, dois modos de ruptura são previstos: aqueles referentes a uma viga flexionada (tensões normais) e também ruptura por cisalhamento.

Contudo, o objetivo principal deste trabalho consistiu na avaliação de dois diferentes modelos de corpo de prova e métodos de ensaio propostos pelas normas brasileira [1] e europeia [2] para comparação dos resultados e avaliação da facilidade de execução dos testes. Verificou-se também a relação $\left(\mathrm{f}_{\mathrm{v} 0, \mathrm{k}} / \mathrm{f}_{\mathrm{c} 0 \text {, } \mathrm{k}}\right)$ de caracterização simplificada proposta pela norma brasileira [1] entre a resistência ao cisalhamento $\left(f_{v 0, k}\right)$ e a resistência à compressão paralela às fibras $\left(\mathrm{f}_{\mathrm{c} 0, \mathrm{k}}\right)$ da madeira no caso de coníferas $\left(\mathrm{f}_{\mathrm{v} 0, \mathrm{k}} / \mathrm{f}_{\mathrm{c} 0, \mathrm{k}}=0,15\right)$ e folhosas $\left(\mathrm{f}_{\mathrm{v} 0, \mathrm{k}} / \mathrm{f}_{\mathrm{c} 0, \mathrm{k}}=0,12\right)$.

\section{MATERIAIS E MÉTODOS}

O teor de umidade das madeiras de Pinus elliottii e Eucalyptus saligna utilizadas, neste caso, foi determinado com base nas recomendações da norma brasileira [1]. Foram confeccionados 12 corpos de prova para cada tipo de madeira e norma analisada, totalizando 48 corpos de prova para a determinação da resistência ao cisalhamento paralelo às fibras, sendo 24 para a norma brasileira e 24 para a norma europeia.

As dimensões utilizadas para os corpos de prova da norma europeia [2] foram $5 \times 5 \mathrm{~cm}$ para a seção transversal e $40 \mathrm{~cm}$ de comprimento. Para o corpo de prova proposto pela norma brasileira [1] as dimensões da seção transversal considerada para o cálculo da resistência ao cisalhamento foram $5 \mathrm{~cm} \mathrm{x} 5 \mathrm{~cm}$.

Na Figura 3 estão apresentadas as dimensões e as configurações para os corpos de prova confeccionados segundos as normas, brasileira [1] e europeia [2], respectivamente. 


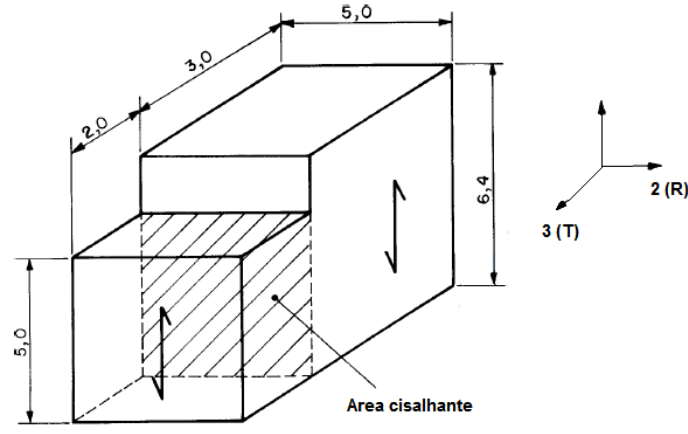

Norma brasileira [1]

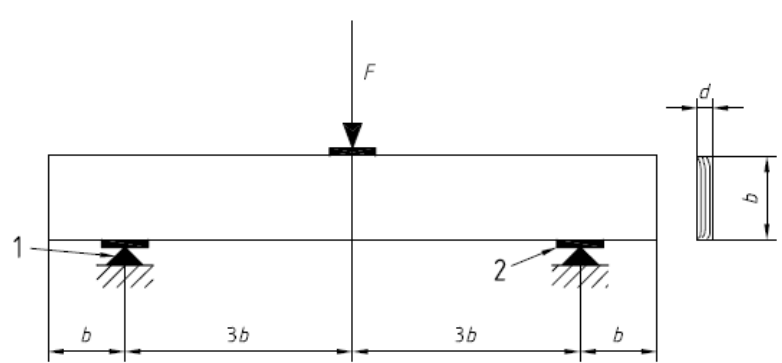

Norma europeia [2]

Figura 3: Configuração dos corpos de prova para determinação da resistência ao cisalhamento paralelo às fibras segundo as normas analisadas.

Os detalhes dos corpos de prova de pinus e eucalipto utilizados nos ensaios experimentais para a determinação da resistência ao cisalhamento na direção paralela às fibras são apresentados na Figura 4 (norma brasileira [1]) e na Figura 5 (norma europeia [2]), respectivamente.

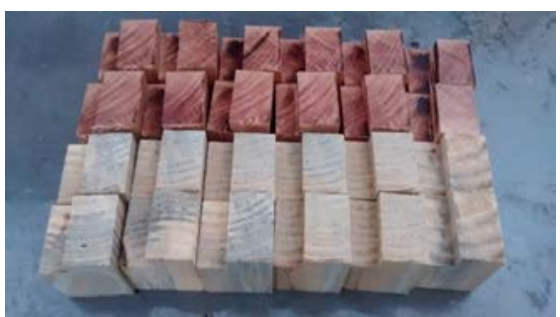

Figura 4: Corpos de prova de Pinus elliottii e Eucalyptus saligna confeccionados de acordo com a norma brasileira [1].
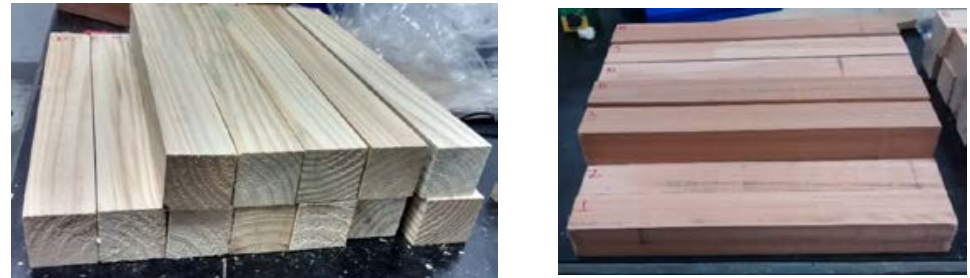

Figura 5: Corpos de prova de Pinus elliottii e Eucalyptus saligna confeccionados de acordo com a norma europeia [2].

Os corpos de prova mostrados na Figura 4 foram submetidos a ensaios de cisalhamento direto e os corpos de prova mostrados na Figura 5 foram submetidos a ensaios de flexão para a determinação da resistência ao cisalhamento. Nos ensaios de flexão segundo a norma europeia [2], o vão entre apoios admitido para os corpos de prova foi de $30 \mathrm{~cm}$.

Os corpos de prova de compressão foram utilizados para a análise das relações $\mathrm{f}_{\mathrm{v} 0, \mathrm{k}} / \mathrm{f}_{\mathrm{c} 0, \mathrm{k}}$ entre a resistência característica ao cisalhamento $\left(\mathrm{f}_{\mathrm{v} 0, \mathrm{k}}\right)$ e a resistência característica a compressão $\left(\mathrm{f}_{\mathrm{c} 0, \mathrm{k}}\right)$, ambas obtidas na direção das fibras. Foram confeccionados, assim, um total de 6 corpos de prova para cada uma das espécies de madeira analisadas (Pinus e Eucalipto), totalizando 12 corpos de prova de compressão com dimensões $5 \times 5 \times 15 \mathrm{~cm}$, seguindo as recomendações da norma brasileira [1].

Os ensaios de resistência à compressão na direção das fibras foram realizados com madeiras com teores de umidades estando no intervalo entre $10 \%$ e $20 \%$. Posteriormente, os valores de resistência e rigidez da madeira foram corrigidos para uma unidade a $12 \%$ de acordo com as Equações 1 e 2, respectivamente, ambas recomendadas pela norma brasileira [1]. Essas equações são válidas quando os valores de umidade da madeira estão contidos entre 10 a $20 \%$.

$$
f_{v 0,12 \%}=f_{u \%}\left[1+\frac{3(U \%-12)}{100}\right]
$$




$$
E_{c 0,12 \%}=E_{u \%}\left[1+\frac{2(U \%-12)}{100}\right]
$$

Todos os ensaios mecânicos de cisalhamento e de caracterização (umidade, densidade, compressão) das madeiras analisadas foram realizados no Laboratório de Propriedades Físicas e Mecânicas da Madeira da Unesp do Campus Itapeva. Para condução dos ensaios mecânicos utilizou-se a máquina universal de ensaios EMIC com capacidade para $300 \mathrm{kN}$. Os detalhes dos ensaios realizados (cisalhamento direto e flexão) na EMIC para a determinação das resistências ao cisalhamento segundo as normas brasileira [1] e europeia [2] e para verificação das relações $\left(\mathrm{f}_{\mathrm{v} 0, \mathrm{k}} / \mathrm{f}_{\mathrm{c} 0, \mathrm{k}}\right)$ de caracterização simplificada da resistência segundo a norma brasileira [1] são apresentados na Figura 6. Na máquina universal de ensaios EMIC os carregamentos nos corpos de prova de cisalhamento direto e de flexão foram aplicados com velocidade de 2,5MPa/min. Os ensaios de compressão foram realizados com velocidade de ensaio de $10 \mathrm{MPa} / \mathrm{min}$.

Vale mencionar também que, no caso dos ensaios de flexão para a determinação da resistência ao cisalhamento segundo a norma europeia [2], a relação entre a distância entre apoios do corpo de prova (30cm) e sua altura $(5 \mathrm{~cm})$ foi igual a 6 , ou seja, $\mathrm{L} / \mathrm{h}<20$, indicando que foi utilizado, neste caso, o modelo de flexão de vigas de Timoshenko. Esse referido modelo considera o efeito do cisalhamento na determinação da flecha no meio do vão, para uma carga concentrada aplicada neste ponto. O modelo de vigas que considera somente o efeito de flexão na parcela da flecha é o modelo de Bernoulli, o qual é válido para vigas de madeira com relação $\mathrm{L} / \mathrm{h}>20$.

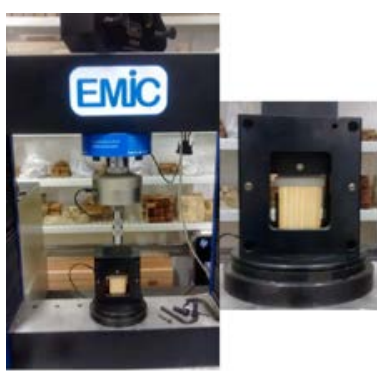

Ensaio de cisalhamento

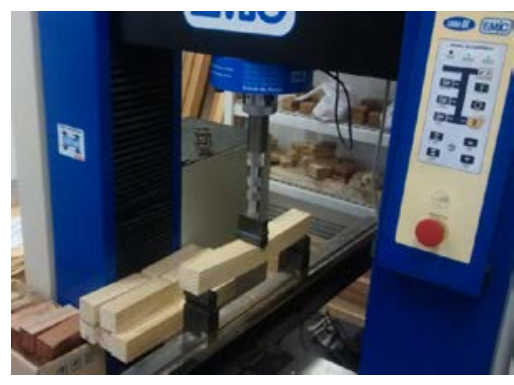

Ensaio de flexão

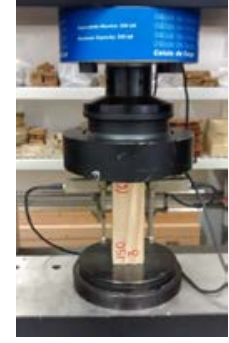

Ensaio de compressão

Figura 6: Ensaios de cisalhamento e flexão realizados segundo as normas brasileira [1] e europeia [2].

A resistência ao cisalhamento $\left(\mathrm{f}_{\mathrm{v}, 0}\right)$ segundo a norma brasileira [1] foi determinada a partir da utilização da Equação 3, também citada em BODIG [11]. O carregamento foi aplicado em um único ciclo de carga, sendo este conduzido até a ruptura por cisalhamento da seção resistente. Na Equação $3 F_{\text {rup }}$ é a força última atingida pelo corpo de prova durante o ensaio e $A$ é a área cisalhante considerada para o corpo de prova.

$$
f_{v, 0}=\frac{F_{\text {rup }}}{A}
$$

No caso da norma europeia [2] a resistência ao cisalhamento foi obtida por meio de ensaios de flexão com carregamento concentrado e aplicado no meio do vão da peça flexionada a partir do uso da Equação 4. O carregamento, neste caso, também foi aplicado em um único ciclo de carregamento até a ruptura. Os parâmetros d e b são, respectivamente, a largura e a altura do corpo de prova de flexão, conforme Figura 3.

$$
f_{v, 0}=\frac{0,75 \cdot F_{r u p}}{d \cdot b}
$$

Os valores característicos das resistências ao cisalhamento e à compressão paralela às fibras para a verificação das relações simplificadas [1], para madeiras de coníferas e dicotiledôneas, foram obtidos por meio da Equação 5, proposta pela norma brasileira [1]. Na equação 5 os valores $f_{1}, f_{2} \ldots f_{n}$ são os valores de resistência ao cisalhamento dos corpos de prova, sendo $n$ o número de corpos de prova ensaiados. Os valores de $n$, neste caso, foram iguais a 12 para cada um dos tipos de madeira. 


$$
f_{w, k}=\left(2 \cdot \frac{f_{1}+f_{2} \cdots+f_{\frac{n}{2}-1}}{\frac{n}{2}-1}-f_{\frac{n}{2}}\right) \times 1,1
$$

As resistências ao cisalhamento obtidas foram analisadas com base em análises estatísticas efetuadas no software R [12], que é um software livre distribuído gratuitamente. As análises estatísticas, neste caso, tiveram a intenção de avaliar se as médias das resistências ao cisalhamento apresentavam diferenças significativas a um nível de significância de 5\%. As análises estatísticas partiram inicialmente da hipótese nula $\left(\mathrm{H}_{0}\right)$, de que as médias da resistência ao cisalhamento das espécies estudadas utilizando as normas brasileira [1] e a europeia [2] eram estatisticamente equivalentes. A outra hipótese $\left(\mathrm{H}_{1}\right)$ foi de que as referidas resistência ao cisalhamento não eram estatisticamente equivalentes. Os testes estatísticos realizados foram: Bartlett's test, Shapiro-Wilk e t-test.

\section{RESULTADOS}

A Tabela 1 apresenta os valores de resistência ao cisalhamento paralelo às fibras das madeiras de Pinus elliotti $\left(\mathrm{E}_{\mathrm{c} 0,12 \%}=20170 \mathrm{MPa}\right)$ corrigidos para o valor padrão referente a $12 \%$ de umidade para ambas as normas estudadas.

A Tabela 2 apresenta os valores de resistência ao cisalhamento paralelo às fibras das madeiras de $E u$ calyptus saligna $\left(\mathrm{E}_{\mathrm{c} 0,12 \%}=25236 \mathrm{MPa}\right)$. A estratégia de se obter os valores de resistência corrigidos para a umidade de $12 \%$ foi adotada para possibilitar a comparação entre os resultados obtidos. A umidade $12 \%$ corresponde à umidade de equilíbrio da madeira, valor de umidade para o qual a madeira praticamente não sofre mais variações dimensionais. Os valores da densidade aparente a $12 \%$, obtidos para as madeiras analisadas foram os seguintes: Eucalyptus saligna $\left(\rho_{12}=742 \mathrm{~kg} / \mathrm{m}^{3}\right)$ e Pinus elliotti $\left(\rho_{12}=520 \mathrm{~kg} / \mathrm{m}^{3}\right)$.

Tabela 1: Resistência ao cisalhamento paralelo às fibras para madeiras de Pinus elliottii com $12 \%$ de umidade.

\begin{tabular}{c|c|c}
\hline CORPO DE PROVA & $\begin{array}{c}\text { NORMA BRASILEIRA [1] } \\
\mathbf{f}_{\mathbf{v} 0}(\mathbf{M P a})\end{array}$ & $\begin{array}{c}\text { NORMA EUROPEIA [2] } \\
\mathbf{f}_{\mathbf{v} 0}(\mathbf{M P a})\end{array}$ \\
\hline 1 & 12,21 & 2,75 \\
\hline 2 & 11,4 & 3,02 \\
\hline 3 & 8,9 & 3,09 \\
\hline 4 & 11,86 & 3,27 \\
\hline 5 & 11,74 & 3,66 \\
\hline 6 & 11,12 & 3,77 \\
\hline 7 & 9,32 & 4,07 \\
\hline 8 & 12,07 & 4,14 \\
\hline 9 & 11,5 & 4,45 \\
\hline 10 & 14,66 & 4,56 \\
\hline 11 & 12,31 & 5,06 \\
\hline 12 & 9,88 & 5,38 \\
\hline Média & 11,41 & 3,94 \\
\hline Desvio Padrão & 1,468 & 0,795 \\
\hline Coef. de variação (\%) & $12,86 \%$ & $20,21 \%$ \\
\hline
\end{tabular}


Tabela 2: Resistência ao cisalhamento paralelo às fibras para madeira de Eucalyptus saligna com 12\% de umidade.

\begin{tabular}{c|c|c}
\hline CORPO DE PROVA & $\begin{array}{c}\text { NORMA BRASILEIRA [1] } \\
\mathbf{f}_{\mathbf{v} 0}(\mathbf{M P a})\end{array}$ & $\begin{array}{c}\text { NORMA EUROPEIA [2] } \\
\mathbf{f}_{\mathbf{v} 0}(\mathbf{M P a})\end{array}$ \\
\hline 1 & 13,26 & 8,41 \\
\hline 2 & 14,23 & 6,78 \\
\hline 3 & 12,21 & 9,27 \\
\hline 5 & 14,91 & 9,16 \\
\hline 6 & 12,96 & 9,3 \\
\hline 7 & 16,38 & 9,36 \\
\hline 8 & 8,1 & 7,93 \\
\hline 9 & 12,2 & 10,04 \\
\hline 10 & 10,24 & 8,46 \\
\hline 11 & 14,13 & 6,23 \\
\hline 12 & 13,28 & 9,56 \\
\hline Média & 13,84 & 6,12 \\
\hline Desvio Padrão & 12,98 & 8,39 \\
\hline Coef. de variação (\%) & 2,166 & 1,343 \\
\hline & $16,69 \%$ & $16,02 \%$ \\
\hline
\end{tabular}

Nas Tabelas 3 e 4 estão os valores característicos obtidos para a resistência ao cisalhamento e para a resistência a compressão paralela às fibras a 12\% de umidade em madeiras de Pinus e Eucalipto.

Tabela 3: Valores característicos da resistência ao cisalhamento para madeiras de Pinus e Eucalipto a 12\% de umidade.

\begin{tabular}{ccc}
\hline & NORMA BRASILEIRA & NORMA EUROPEIA \\
ESPÉCIE & $\begin{array}{c}\text { [1] } \\
\mathbf{f}_{\mathrm{v} 0, \mathrm{k}}(\mathrm{MPa})\end{array}$ & $\begin{array}{c}\text { [2] } \\
\mathbf{f}_{\mathrm{v} 0 \mathrm{k},}(\mathrm{MPa})\end{array}$ \\
\hline Pinus elliottii & 9,62 & 3,04 \\
Eucalytus saligna & 9,93 & 6,30 \\
\hline
\end{tabular}

Tabela 4: Valores característicos da resistência à compressão paralela para Pinus e Eucalipto a 12\% de umidade.

\begin{tabular}{ccccc}
\hline \multicolumn{2}{c}{ PINUS ELLIOTTI } & \multicolumn{3}{c}{ EUCALYPTUS SALIGNA } \\
\hline & $\mathrm{f}_{\mathrm{c} 0}$ & $\mathrm{f}_{\mathrm{c} 0, \mathrm{k}}$ & $\mathrm{f}_{\mathrm{c} 0}$ & $\mathrm{f}_{\mathrm{c} 0, \mathrm{k}}$ \\
$(\mathrm{MPa})$ & $(\mathrm{MPa})$ & $(\mathrm{MPa})$ & $(\mathrm{MPa})$ \\
\hline 1 & 42 & & 76 & \\
2 & 48 & & 75 & \\
3 & 49 & & 72 & \\
4 & 37 & & 72 & \\
5 & 36 & 33 & 77 & $\mathbf{7 6}$ \\
6 & 32 & & 77 & \\
Média (MPa) & 41 & & 75 & \\
Desvio padrão & 6,80 & & 2,36 & \\
Coef. de variação (\%) & 17 & & 3,17 & \\
\hline
\end{tabular}

O primeiro teste estatístico realizado foi o Bartlett’s test para a verificação da homogeneidade dos dados. Para o Pinus elliottii foi obtido um p-value de 0,05304, enquanto que para o Eucalyptus saligna o pvalue obtido foi de 0,1283 . Esses valores indicaram a homogeneidade dos dados para ambas as madeiras ana- 
lisadas. Em seguida, para verificação da normalidade dos dados, foi realizado o teste de Shapiro-Wilk. Neste caso, os p-values obtidos para as resistências ao cisalhamento do Pinus elliotti e do Eucalyptus saligna foram iguais a 0,002611 e 0,2423, respectivamente, indicando a normalidade dos dados. Por fim, foi realizado o $t$ test para a comparação das médias obtidas para a resistência ao cisalhamento paralelo às fibras segundo as normas estudadas. Para o Pinus elliottii o p-value do t-test foi de $3,809 \mathrm{e}^{-11}$ e para o Eucalyptus saligna foi obtido um $p$-value igual a $6,265 \mathrm{e}^{-06}$, indicando que para ambas as madeiras as médias obtidas a partir da norma brasileira [1] e europeia [2] diferiram entre si. As comparações das resistências ao cisalhamento na direção das fibras $\left(\mathrm{f}_{\mathrm{v} 0}\right)$ para normas brasileira [1] e europeia [2] são apresentadas nos gráficos boxplot das Figuras 7 e 8 . A Figura 7 refere-se aos dados das madeiras de Eucalyptus saligna e a Figura 8 aos dados de Pinus elliotti. É possível observar, nestes casos, a distribuição empírica dos dados.

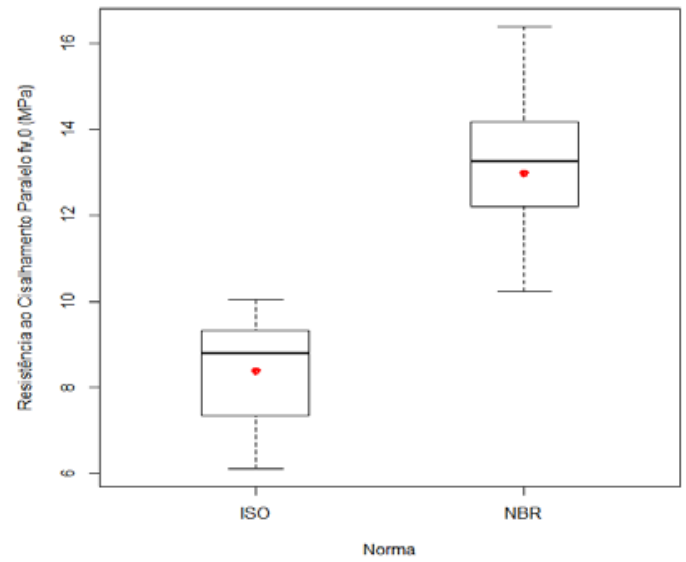

Figura 7: Boxplot para a análise das resistências ao cisalhamento paralelo às fibras em madeiras de Eucalyptus saligna determinadas segundo as normas brasileira [1] e norma europeia [2].

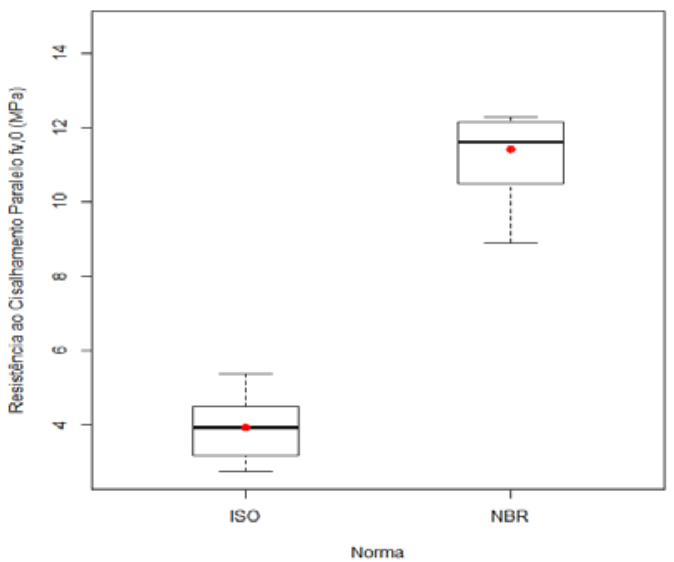

Figura 8: Boxplot para a análise das resistências ao cisalhamento paralelo às fibras em madeiras de Pinus elliottii determinadas segundo as normas brasileira [1] e norma europeia [2].

A avaliação da Figura 7 mostra que para a norma europeia [2] (representada pela caixa esquerda) a mediana (valores entre 8 e 10) e limite superior foram relativamente menores que a mediana (valores entre 12 e 14) e limite superior obtidos para a norma brasileira [1] (representada pela caixa direita). No entanto, a dispersão dos dados foi mais uniforme para as resistências ao cisalhamento obtidas segundo a norma europeia [2] quando comparada com a norma brasileira [1]. Observa-se também, a partir desse gráfico, de uma maneira geral, que os valores de resistência ao cisalhamento para madeiras de Eucalyptus saligna obtidos segundo a norma brasileira [1] foram relativamente superiores aos valores de resistência obtidos segundo a norma europeia [2]. Além disso, na Figura 8, para madeiras de Pinus elliotti, observou-se um resultado semelhante no que se refere às diferenças entre as medianas e limites superiores das caixas esquerda e direita. No entanto, a dispersão dos dados foi menos uniforme para a norma brasileira [1] quando comparada com a norma europeia [2], neste caso.

Alguns dos modos de ruptura obtidos para os corpos de prova utilizados para a determinação da resistência ao cisalhamento segundo as normas avaliadas são mostrados na Figura 9. A forma de ruptura observa- 
da nos corpos de prova ensaiados segundo a norma brasileira [1] foi o cisalhamento paralelo às fibras ocorrido na seção de corte (Figura 9a). Para os corpos de prova ensaiados pela norma europeia [2] duas formas de ruptura foram observadas: tensão normal de tração nas fibras inferiores, na parte central do corpo de prova, tipo de ruptura este para o qual a madeira não esgota sua capacidade resistente ao cisalhamento (Figura 9c). Para as madeiras de Eucalipto essa foi a forma de ruptura predominante A segunda forma de ruptura obtida conforme a proposta da norma europeia foi o cisalhamento por flexão ao longo do comprimento do corpo de prova nas regiões próximas a linha neutra da seção (Figura 9b). Neste segundo caso, a forma de ruptura dependeu, portanto, do tipo de madeira (Pinus ou Eucalipto) e também da disposição da direção das fibras (radial ou tangencial) na seção transversal da peça. Vale mencionar que ambos os modos de ruptura obtidos nos ensaios de flexão realizados segundo a norma europeia [2] são previstos pela referida norma. Neste caso, independentemente do modo de ruptura obtido o valor da força última encontrado no ensaio é admitido no cálculo da resistência ao cisalhamento segundo a Equação 4.

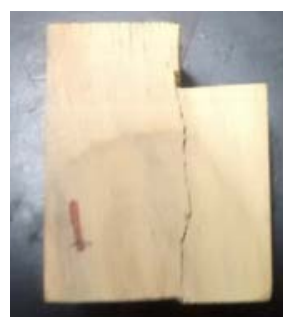

(a) Cisalhamento puro [1]

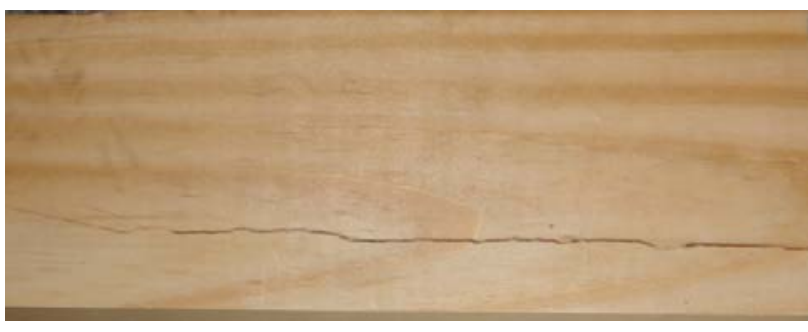

(b) Cisalhamento na flexão [2]

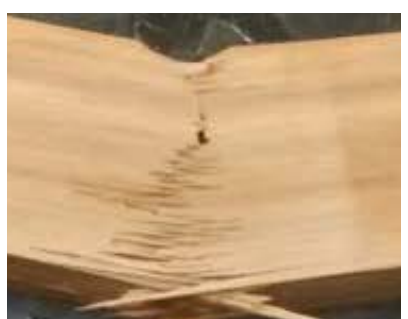

(c) Tensão normal de tração [2]

Figura 9: Modos de ruptura obtidos para os corpos de prova de cisalhamento ensaiados segundo as normas brasileira [1] e europeia [2].

A relação $\mathrm{f}_{\mathrm{v} 0, \mathrm{k}} / \mathrm{f}_{\mathrm{c} 0, \mathrm{k}}$ obtida experimentalmente para as madeiras de Pinus elliotti foi de 0,292 e para as madeiras de Eucalyptus saligna a relação encontrada foi de 0,130.

\section{DISCUSSÃO}

Nas Tabelas 1 e 2, de uma maneira geral, os valores das resistências ao cisalhamento obtidas com base na norma brasileira [1] foram maiores que os valores das resistências ao cisalhamento obtidas pela norma europeia [2]. Para madeiras de Eucalyptus saligna a diferença entre os valores obtidos foi de aproximadamente 65,46\% e para madeiras de Pinus elliotti de 35,36\%. Esse fato pode ser associado ao modo de ruptura obtido, que está associado à disposição da direção das fibras (radial e tangencial) na seção transversal do corpo de prova de flexão. De uma maneira geral, no caso das madeiras de eucalipto, os corpos de prova não atingiram sua capacidade resistente ao cisalhamento. Para os corpos de prova de flexão com madeiras de pinus, com a direção tangencial das fibras orientada no sentido da altura do corpo de prova os valores de resistência tenderam a serem maiores se aproximando do comportamento observado para os corpos de prova com madeiras de eucalipto. Para os corpos de prova com a direção radial orientada no sentido da altura do corpo de prova, menores valores de resistência foram observados e a peças rompera, neste caso, predominantemente por cisalhamento (Figura 9b).

Portanto, de uma maneira geral, a ruptura do corpo de prova proposto pela norma brasileira [1] ocorreu em $100 \%$ dos corpos de prova por cisalhamento puro na seção de corte, como já esperado. Para os ensaios ensaiados a flexão segundo a norma europeia [2], aproximadamente 75\% (09 corpos de prova) dos corpos de prova de pinus romperam por tensão normal de tração na fibra inferior e os $25 \%$ restantes (03 corpos de prova) romperam por cisalhamento nas regiões da linha neutra da seção orientado ao longo do comprimento da peça. Para os corpos de prova de eucalipto, $100 \%$ dos modos de ruptura foram por tensão normal de tração.

A titulo de informação os valores das resistências ao cisalhamento, fornecidos pela norma europeia EN 338 [13], para coníferas com classes de resistência C20 e C30 são, respectivamente, 3,6 MPa e 4,0 MPa. Para dicotiledôneas (folhosas) com classes de resistência D30 e D60, os valores de resistência ao cisalhamento são de 4,0MPa e 4,5 MPa, respectivamente. De acordo com a norma brasileira [1], para as coníferas, os valores das resistências ao cisalhamento fornecidos para as classes de resistência C20 e C30 são, respectivamente, 4,0 MPa e 6,0 MPa. Para as dicotiledôneas a norma brasileira fornece valores de resistência ao cisalhamento iguais a 5,0 MPa e 8,0 MPa para as classes de resistência correspondentes a D30 e D60, respecti- 
vamente. Observa-se que os valores das resistências ao cisalhamento fornecidos pela norma europeia [13] são relativamente menores que os valores fornecidos pela norma brasileira.

Portanto, nos corpos de prova de flexão ensaiados segundo a norma europeia [2], os modos de ruptura ocorrem por esforços combinados de tração na fibra inferior e compressão nas fibras superiores ou por cisalhamento próximo a linha neutra da seção, modos de ruptura estes previstos pela referida norma. Nos corpos de prova propostos pela norma brasileira [1] a ruptura por cisalhamento é condicionada a ocorrer na seção de corte e muitas vezes não representa uma situação real de ocorrência prática.

As relações $\mathrm{f}_{\mathrm{v} 0, \mathrm{k}} / \mathrm{f}_{\mathrm{c} 0, \mathrm{k}}$ propostas pela norma brasileira [1] para pinus e eucalipto são de 0,15 e 0,12 , respectivamente. A relação $f_{\mathrm{v} 0, \mathrm{k}} / \mathrm{f}_{\mathrm{c} 0, \mathrm{k}}$ obtida experimentalmente para as madeiras de Pinus elliotti foi de 0,292 e para as madeiras de Eucalyptus saligna a relação encontrada foi de 0,130.

\section{CONCLUSÕES}

O método de ensaio proposto pela norma brasileira [1] para a determinação da resistência ao cisalhamento paralelo às fibras forneceu um valor médio de resistência $\left(\mathrm{f}_{\mathrm{c} 0, \mathrm{~m}}\right)$ maior que o valor de resistência ao cisalhamento proposto pela norma europeia [2]. Para madeiras de Eucalyptus saligna a diferença entre os valores obtidos foi de aproximadamente $65,46 \%$ e para madeiras de Pinus elliotti a diferença foi de 35,36\%.

A relação $f_{\mathrm{v} 0, \mathrm{k}} / \mathrm{f}_{\mathrm{c} 0, \mathrm{k}}$ para madeiras de Eucalyptus saligna foi muito próxima da relação proposta pela norma brasileira [1] para dicotiledôneas. Para madeiras de Pinus elliotti a relação experimental obtida foi aproximadamente $48 \%$ maior que a relação proposta pela norma brasileira para coníferas.

O corpo de prova e metodologia propostos pela norma brasileira [1] fornecem um valor de resistência ao cisalhamento puro para madeiras do tipo coníferas e dicotiledôneas. O modo de ruptura, neste caso, é condicionado a ocorrer na seção de corte do corpo de prova isento de defeitos e por esse motivo a resistência ao cisalhamento tende a apresentar um valor maior.

Por outro lado, o corpo de prova e metodologia propostos pela norma europeia [2] fornecem valores menores de resistência ao cisalhamento [13] quando comparados com os valores fornecidos pela norma brasileira [1]. Os modos de ruptura previstos pela norma europeia para o ensaio de flexão (por tensões normais de tração e por cisalhamento ao longo do comprimento do corpo de prova, na altura próxima a linha neutra da seção) foram observados nos ensaios realizados, neste caso, com madeiras de Pinus elliotti e Eucalyptus saligna. Para $100 \%$ dos corpos de prova de eucalipto e aproximadamente $75 \%$ dos corpos de prova de pinus com direção tangencial das fibras orientadas no sentido da altura do corpo de prova o modo de ruptura observado foi por tensões normais. Em $25 \%$ dos corpos de prova de pinus com a direção radial das fibras orientadas no sentido da altura do corpo de prova o modo de ruptura foi por cisalhamento direcionado ao longo do comprimento da peça.

A relação $\mathrm{f}_{\mathrm{v} 0, \mathrm{k}} / \mathrm{f}_{\mathrm{c} 0, \mathrm{k}}$ avaliada para madeiras de Pinus elliotti e Eucalyptus citriodora indicou ser mais representativa em madeiras mais duras (eucalipto).

\section{AGRADECIMENTOS}

Ao Laboratório de Propriedades Mecânicas dos Materiais da UNESP de Itapeva por ceder as instalações possibilitando a realização desta pesquisa.

\section{BIBLIOGRAFIA}

[1] ASSOCIAÇÃO BRASILEIRA DE NORMAS TÉCNICAS, NBR 7190, Projeto de Estruturas de Madeira, 107p, Rio de Janeiro, 1997.

[2] INTERNATIONAL STANDARD, ISO 13910, Structural timber - Characteristic values of strengthgraded timber — Sampling, full-size testing and evaluation, 30p, Switzerland, 2005.

[3] RITTER, M. A. (1990), Timber Bridges: Design, Construction, Inspection, and Maintenance: manual.1 ed., Washington, Forest Service USA.

[4] SANTOS NETO, A.B.S., "Proposta de ensaio para cisalhamento paralelo as fibras", In: IV Encontro Brasileiro de Madeiras e em Estruturas de Madeira, pp. 135-143, Florianópolis, 1998.

[5] SCANAVACA JUNIOR, L., GARCIA, J.N., "Determinação das propriedades físicas e mecânicas da madeira de Eucalyptus urophylla”, Scientia Forestalis, v. 1, n. 65, pp. 120-129, Jun. 2004.

[6] NASCIMENTO, A. M., OLIVEIRA, J.T.S., DELLA LUCIA, R.M., "Classificação e propriedades da madeira de pinus e eucalipto”, Floresta e Ambiente, v. 8, n. 1, pp. 27-35, Dez. 2001. 
[7] RODRIGUES, R.A.D., Variabilidade de propriedades físico mecânicas em lotes de madeira serrada de eucalipto para a construção civil, Dissertação de M.Sc., Ciência e Tecnologia da Madeira/USP, Piracicaba, SP, 2002.

[8] HARA, M.M., Proposta de método de ensaio para determinação da resistência ao cisalhamento paralelo as fibras de madeiras mediante esforço induzido por puncionamento do corpo de prova, Dissertação de M.Sc., Programa de Pós-graduação em Engenharia Civil/UTFPR, Curitiba, PR, 2011.

[9] XAVIER, J.M.C., Caracterização do comportamento ao corte da madeira usando o ensaio de iosipescu. 2003, Dissertação de M.Sc., Tecnologias das Engenharias/Universidade de Trás-os-montes e Alto Douro, Vila Real, 2003.

[10] BRAND, M.A., KRAMBECK, L.B.P., SIMAO R.L., "Ensaio Experimental de espécies do gênero Pinus na avaliação das propriedades mecânicas da madeira”: In: III Encontro de ciência e tecnologia, pp. 1-15, Lages, Nov. 2004.

[11] BODIG, J., JAYNE, B.A., Mechanics of wood and wood composites, 2. ed., Florida, Krieger Publishing Company, 1993.

[12] R SOFTWARE (2015), The R Project for Statistical Computing, versão 3.2.3, R Development Core Team.

[13] EUROPEAN STANDARD, EN 338, Structural timber - Strength classes, 14p, Paris, 2012. 